\title{
Pediatric cardiac transplantation: Three-dimensional printing of anatomic models for surgical planning of heart transplantation in patients with univentricular heart
}

\author{
Ralf Sodian, MD, ${ }^{\mathrm{a}}$ Stefan Weber, PhD, ${ }^{\mathrm{c}}$ Mathias Markert, MSc, ${ }^{\mathrm{c}}$ Markus Loeff, MD, ${ }^{\mathrm{b}}$ Tim Lueth, PhD, ${ }^{\mathrm{c}}$ Florian C. Weis, MD, \\ Sabine Daebritz, MD, ${ }^{a}$ Edward Malec, MD, ${ }^{a}$ Christoph Schmitz, MD,${ }^{a}$ and Bruno Reichart, MD, ${ }^{a}$ Munich and Garching, Germany
}

Orthotopic heart transplantation is definitive therapy for infants with failing staged palliation after univentricular repair. ${ }^{1}$ Although the surgical management of these patients may be quite straightforward, the actual cardiac and vascular anatomy is sometimes unpredictable. To overcome this problem, we developed a new technique to fabricate a custom made replica from 128-slice computed tomographic (CT) and magnetic resonance imaging (MRI) angiography to create a realistic model of the anatomic situation for preoperative assessment and intraoperative orientation in 2 patients with failed staged palliation. In such situations, solid replicas may be helpful in choosing surgical treatment strategies before heart transplantation, for intraoperative orientation, and in demonstrating the planned procedure to patients and parents with lifelike models.

\section{CLINICAL SUMMARY}

We studied 2 patients with failing single-ventricle repair who had undergone multiple surgical interventions and were finally listed for heart transplantation. Patient 1 was a 2year-old boy who had failing staged palliation of hypoplastic left heart syndrome. He had undergone a Norwood stage 1 operation, a Glenn superior cavopulmonary anastomosis, and a repair of the tricuspid valve. The patient had severe tricuspid regurgitation and heart failure after the second stage of the reconstruction and was therefore listed for transplantation.

Patient 2 was a 14-year-old girl who had pulmonary atresia and a hypoplastic right ventricle without ventricular septal defect. She had undergone modified Blalock-Taussig shunt placement on the right side during her first month of life. A central shunt was created when she was 16 months old. The patient did well for the next 5 years. When she was 9 years old, a bidirectional Glenn anastomosis was performed. One year later, a total cavopulmonary connection was performed with an 18-mm Gore-Tex vascular graft (W. L. Gore \& Associates, Inc, Flagstaff, Ariz). Five years after this operation, the

\footnotetext{
From the Departments of Cardiac Surgery, ${ }^{\text {a }}$ Pediatric Cardiology, Ludwig-MaximiliansUniversity, Munich, Germany, ${ }^{\mathrm{c}}$ and the Institute of Micro Technology and Medical Device Technology, Technical University Munich, Garching, ${ }^{\mathrm{b}}$ Germany.

Received for publication Nov 26, 2007; accepted for publication March 23, 2008.

Address for reprints: Ralf Sodian, MD, Department of Cardiac Surgery, Ludwig-Max imilians-University, Marchioninistrasse 15, 81377, Munich, Germany (E-mail: ralf. sodian@med.uni-muenchen.de).

J Thorac Cardiovasc Surg 2008;136:1098-9

$0022-5223 / \$ 34.00$

Copyright (C) 2008 by The American Association for Thoracic Surgery doi:10.1016/j.jtcvs.2008.03.055
}

patient was admitted to our institution with signs and symptoms of a severe protein-losing enteropathy after the Fontan procedure. Medical treatment remained unsuccessful, and the girl was finally listed for heart transplantation.

In these cases, the volumetric data were processed with MeVisLab-Environment (MeVis Research, Bremen, Germany). The image data were obtained from a single CT or MRI scan (Digital Imaging and Communications in Medicine [DICOM] format). After the volume was cropped, the images were segmented with application of a region-growing algorithm. To obtain completely the preliminarily selected vascular structures, the threshold values were adjusted manually to match the borders of all structures. For creation of a surface model, a marching cube algorithm was applied. Before export of the surface data to the stereolithography machine (ZCorp, Burlington, Mass), the surface was smoothed to compensate for coarseness caused by the segmentation. The smoothing did not have any effect on the characteristics of the vascular structures of the model. For 3-dimensional (3D) printing (inkjet printing technology), the size information from the DICOM file was applied. As the size of the printed 3D model was calibrated with less than $1 \mathrm{~mm}$, the size of the model matched pictured structures. ${ }^{2}$ With these data linked to the rapid-prototype stereolithography equipment, we were able to fabricate a luminal replica of the anatomy in these patients with failed single-ventricle repair. In the newly created models, the anatomic structures important for heart transplantation, such as the single ventricle, the ascending aorta and aortic arch, the pulmonary arteries and Glenn anastomosis, the brachiocephalic vein, the superior vena cava, the inferior vena cava, and the extracardiac Fontan tunnel (in patient 2) could be reconstructed (Figures 1 and 2). On the basis of the added anatomic understanding, the procedures for the fourth operation (patient 1) and the sixth operation (patient 2) were determined. In addition, it was possible to sterilize the model and take it into the operating room for better intraoperative orientation.

\section{DISCUSSION}

We previously reported the use of stereolithographic models in the correction of congenital defects with complex vascular anatomy or reoperation, cases in which surgery is often complicated by excessive scar tissue formation. ${ }^{3}$ In patients with failing staged palliation after Norwood stage I operation, a Glenn superior cavopulmonary anastomosis, or 


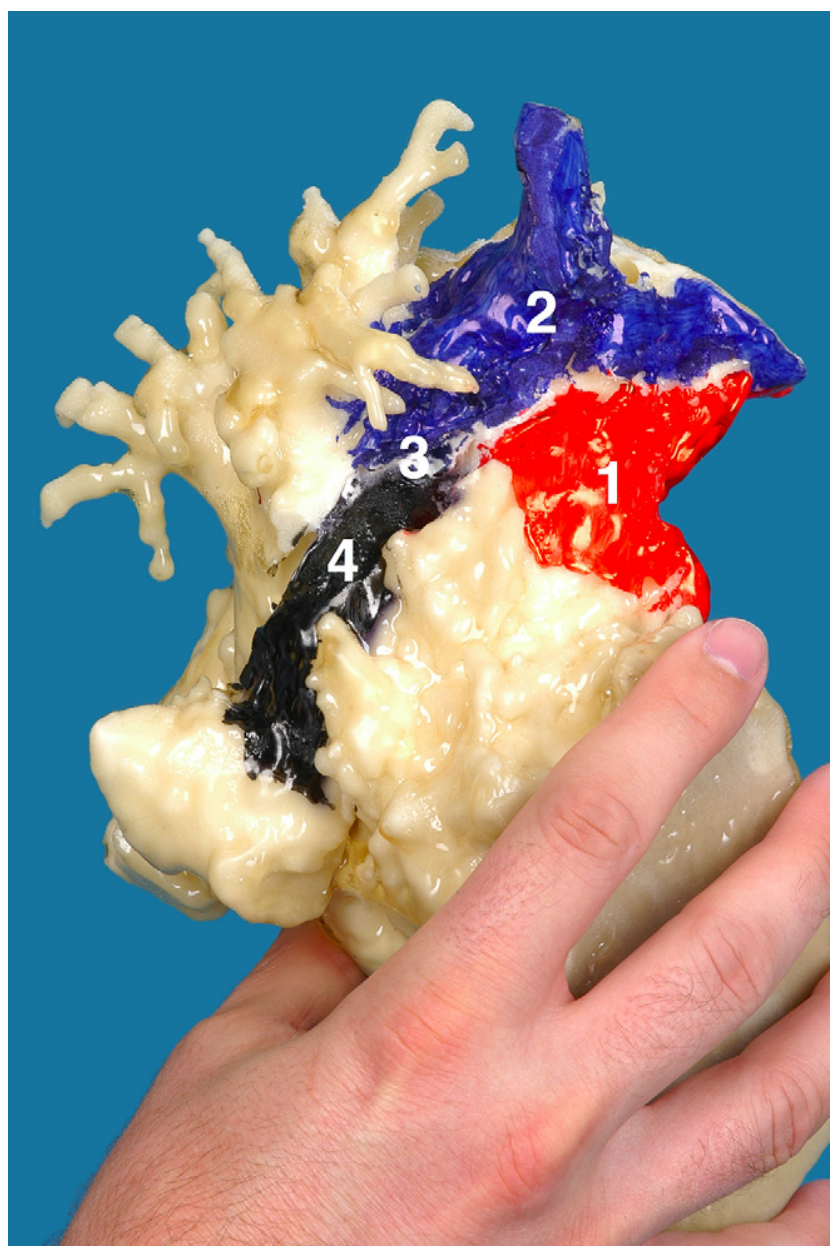

FIGURE 1. Stereolithographic model of patient 2 (side view): ascending aorta and aortic arch (1), brachiocephalic vein and superior vena cava (2), right pulmonary artery with Glenn anastomosis and Fontan anastomosis (3), and extracardiac Fontan tunnel (4).

a Fontan completion operation, however, heart transplantation offers the only chance of survival. Transplantation in this subgroup of patients carries a high risk. These patients have already undergone several reoperations, and the surgical planning and intraoperative orientation are therefore often extremely complicated. ${ }^{4}$

Our experience demonstrates the utility of lifelike 3D replicas in surgical planning of heart transplantation in patients with failing staged palliation of hypoplastic left heart syndrome. In our experience, it was possible to use currently available MRI and CT technology to fabricate accurate models of the anatomy of these patients.

Both patients had already undergone multiple corrective procedures and therefore had fairly unpredictable anatomy for heart transplantation. To overcome these shortcomings, our group applied rapid-prototyping techniques to fabricate models of these hearts after failing staged palliation.

We do not believe that such models are necessary in all pediatric heart transplant cases, but they allow the surgeon

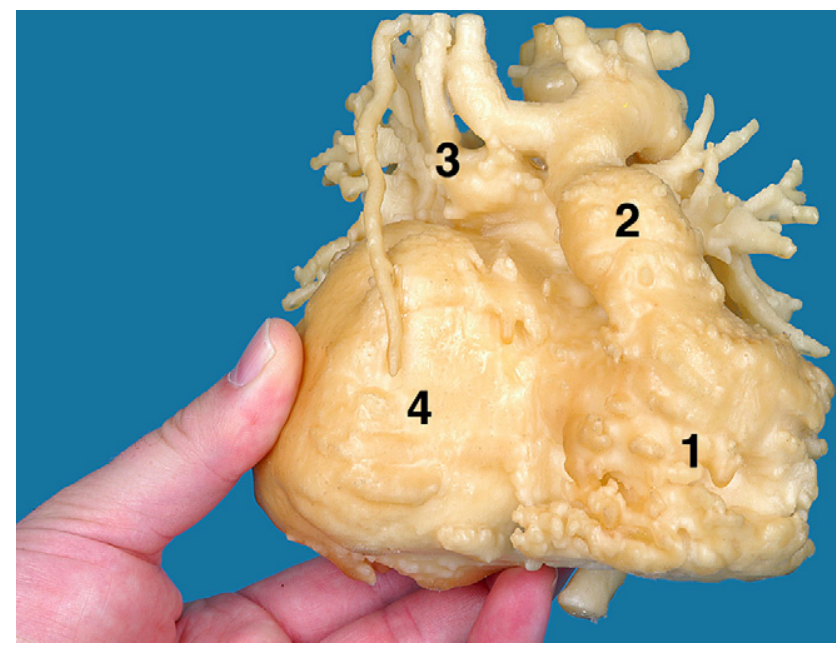

FIGURE 2. Stereolithographic model of patient 1 (frontal view): single ventricle (right ventricle, 1 ), ascending aorta and aortic arch (2), Glenn anastomosis (3), and inferior vena cava and extremely dilated atrium (4).

better understanding of patient-specific 3D anatomy for this complex subgroup of patients. Moreover, the surgeon is able to hold an exact replica of the patient's heart and examine it from different angles. This allows the surgeon and the pediatric cardiologist to develop the optimal surgical approach during heart transplantation and to anticipate problems that may arise during dissection or implantation of the heart. The specific dimensions and distances can be measured, and heart transplantation can be planned preoperatively. Moreover, together with the transplant surgeon, the explant team receives detailed information about special dimensions and requirements of the donor heart (eg, superior and inferior vena cava, pulmonary artery, and aortic arch).

In conclusion, these experiences show that it is possible to fabricate 3D models of the hearts of patients with univentricular hearts and failed staged palliation by means of routine MRI or CT scan and rapid-prototyping technology. The stereolithographic models provide great theoretic and practical advantages for surgeons, cardiologists, researchers, and teachers because they can be used to demonstrate lifelike anatomy.

We thank Anne Gale, ELS, of the Deutsches Herzzentrum Berlin, for editorial assistance in the preparation of the manuscript.

\section{References}

1. d'Udekem Y, Iyengar AJ, Cochrane AD, Grigg LE, Ramsay JM, Wheaton GR, et al. The Fontan procedure: contemporary techniques have improved long-term outcomes. Circulation. 2007;116(11 Suppl):I157-64.

2. Weber S, Sodian R, Markert M, Reichart B, Daebritz S, Lueth TC. 3D printing of anatomical heart models for surgical planning in cardiac surgery. Int J CARS. 2007; 2:171-3.

3. Sodian R, Weber S, Markert M, Rassoulian D, Kaczmarek I, Lueth TC, et al. Stereolithographic models for surgical planning in congenital heart surgery. Ann Thorac Surg. 2007;83:1854-7.

4. Chaudhari M, Sturman J, O'Sullivan J, Smith J, Wrightson N, Parry G, et al. Rescue cardiac transplantation for early failure of the Fontan-type circulation in children. J Thorac Cardiovasc Surg. 2005;129:416-22. 